\title{
MODELLING AND OPTIMIZATION OF MAGNESIUM ALLOY MILLING PARAMETERS
}

\author{
Bogdan Chirita, Catalin Tampu, Eugen Herghelegiu, Cosmin Grigoras
}

Faculty of Engineering, "Vasile Alecsandri" University of Bacau, Bacau, 600115, Romania

Corresponding author: Bogdan Chirita, chib@ub.ro

\begin{abstract}
In the pursuit to lighter, less consuming products, manufacturers, especially in aviation and automotive industries, are turning more and more to using lightweight alloys such as the ones based on magnesium. Higher requirements for increased productivity have led to concepts like high-speed machining (HSM), high feed machining (HFM) or high-efficiency machining. Tighter regulations concerning requiring for more environmentally friendly industrial processes led to limitations in the use of cooling liquids and a search for cooling methods with less impact (dry cutting, cryogenic cooling, near dry machining and others). Better machining processes can only be achieved by modelling and optimization. This paper briefly presents the results obtained by our research team concerning the modelling and optimization attempts on face milling of magnesium alloys using different methods: design of experiments (e.g. factorial design, response surface method), fuzzy logic or neural networks.
\end{abstract}

Key words: optimization, magnesium alloy, fuzzy logic, design of experiments.

\section{INTRODUCTION}

Machining is a class of manufacturing processes consisting in the removal of certain layers of material from a workpiece in order to obtain a finished part, according to certain technical, economic or quality requirements. Machining is widely used in industry due to its versatility, high precision, raised productivity and economic efficiency.

The demands for higher productivity and increased efficiency in fabrication have led to the development of concepts such as high-speed machining (HSM), also known as high-performance machining [1], highfeed machining (HFM) [2], and high-efficiency machining that uses a combination of medium cutting speeds and high feed values.

Tighter regulations demanding a lower impact on the environment have led to limitations in using cooling liquids and to search alternative cooling methods such as dry cutting [3, 4], cryogeny [5, 6] and near dry machining which uses minimum amounts of lubricant (minimum quantity lubrication, MQL) [7, 8].
Milling is a highly versatile machining process that allows to generate plane or profiled surfaces. The multiple edged tools with teeth that can engage simultaneously at high cutting speed make the process very productive. Face milling is the operation that uses a tool with the edges placed on the frontal side and circumferential to generate high quality plane surfaces. Light alloys is a generic name for aluminium, magnesium and titanium based alloys, which have gained an extended use in machine building, especially in automotive, aeronautic, electronics, sport equipment and medical industry. This is due especially to a very favourable specific weight to mechanical properties ratio, which make light alloys a viable alternative to other metals as constructive material for structural parts. Their good machinability, corrosion resistance, thermal properties, and, sometimes, biocompatibility offer further advantages.

Machinability of magnesium and aluminium alloys is considered very good, with the cutting forces between a quarter and one third from the ones required for steel machining. The reduced cutting forces combined with the excellent thermal conductivity led to extended tool durability and allowed the use of more intensive cutting regimes. The main issue in their machining are the adhesion phenomena (buld-up edge, flak build-up) that affect surface quality, dimensional precision, and tool life [8-10]. Magnesium alloys machining also requires an increased precaution due to ignition risk. Carou et al. have conducted several studies on magnesium alloys machinability, their applications, and the ignition risk $[11,12]$. Heat treatment may improve machinability of magnesium alloy but also reduce corrosion resistance [13]. Several studies have addressed the effect of cooling and lubrication conditions on the outcomes of the process: temperatures, cutting forces, surface quality, tool wear or residual stress [14- 16].

This paper briefly presents the results obtained by our research team concerning the modelling and optimization attempts on face milling of magnesium alloys using different methods: design of experiments 
(e.g. factorial design, response surface method) and fuzzy logic or neural networks.

\section{MODELLING AND OPTIMIZATION METHODS}

Milling is influenced by a multitude of factors, not all of them measurable, such as the workpiece, the tool, cooling conditions, cutting parameters, whereas the outcomes of the process can be related to physical measures (cutting forces and moments, temperatures etc.) and technico-economical aspects (surface integrity, precision, productivity etc.). While most of the factors can be kept under control, there are also random influences that may affect the results of the process. Nowadays, the importance of modelling and simulation has increased, stimulated especially by the evolution of information technology [17].

The choice of the optimal parameters for machining has a defining role to ensure product quality, decrease production costs and increase productivity. Any process modelling and optimization require extended knowledge about the respective process, a set of equations to determine boundary conditions, the choice of the optimization criteria, and knowledge about mathematical and numerical optimization methods and techniques.

Due to the complex nature of the cutting process and the large number of variables, it is very difficult to seek an optimal solution. An efficient solving method is to find a relationship between process performances and input parameters using mathematical and optimization techniques based on appropriate algorithms. The methods used for the analysis and optimization of machining processes are often based on experimental design, neural networks, genetic algorithms, fuzzy logic.

\subsection{Fuzzy logic}

Developed by L. Zadeh in 1965, fuzzy logic theory offers the means to operate with linguistic terms such as "much", "less", "often", "seldom" etc. through a mathematical model capable to mimic human reasoning ability. Fuzzy systems are thus capable of modelling complex problems that use uncertain data with increased risk levels.

Classic logic is based on a binary system that uses "crisp" sets, where the membership of an element to the set is described by two values: 0 when it does not belong and 1 when it belongs to the set. Fuzzy logic proposes the concept of "degree of membership" that can have any value within the real continuous interval $[0,1]$. The degree of membership of an element to the fuzzy set express the degree of compatibility between the element and the fuzzy set. The element $x$ belongs to the set $A$ with a certain degree $a(x)=\operatorname{Degree}(x \in A) \quad$ and the map $a: X \rightarrow\{$ Membership Degrees $\}$ is called a membership function. The fuzzy set is expressed as $A=\{(x, a(x))\}, x \in X$ and it imposes an elastic constrain of the possible values of the elements $x$ called the possibility distribution [18]. Several shapes may be used for the membership functions (Figure 1).
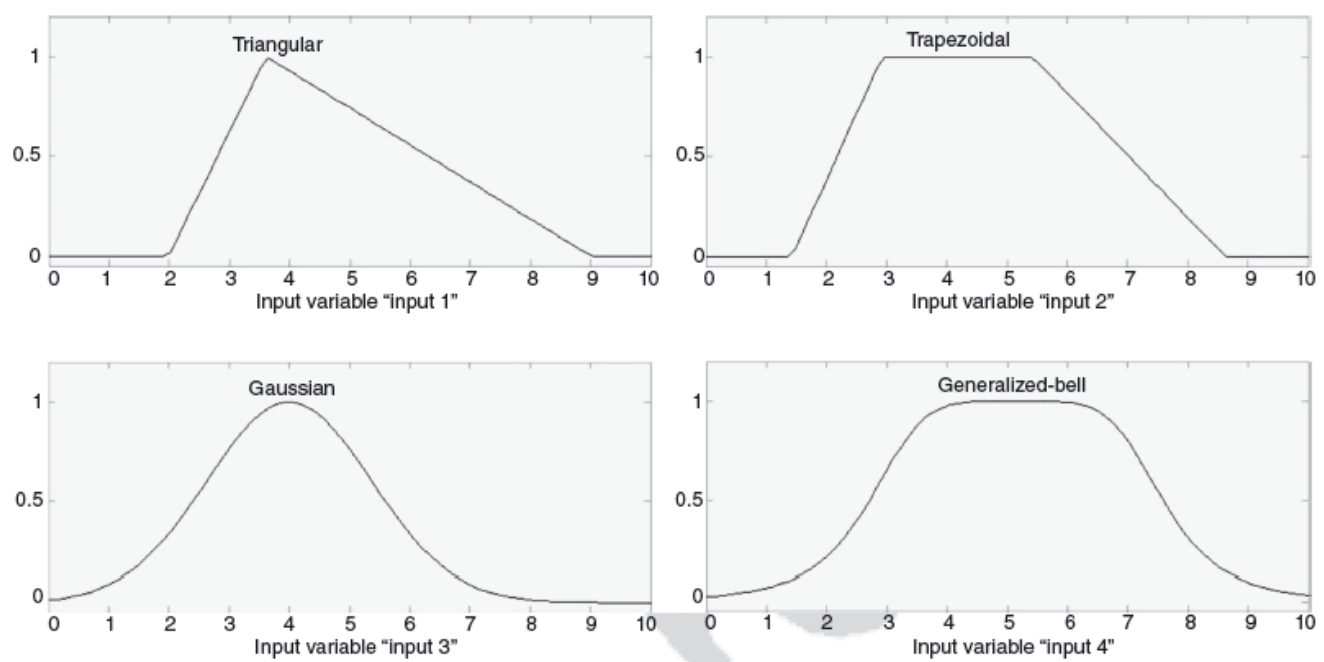

Fig. 1. Membership functions [17]

Fuzzy inference systems (FIS) are decisional systems using fuzzy conditional IF-THEN rules and logical operators like "AND" and "OR" to construct a set of decision rules. It is often necessary to convert crisp values into fuzzy sets, a process called fuzzification. Several membership functions may be used to convert an input parameter in its entire range of variation, whereas the membership degrees can be assigned by intuition, inference, rank ordering, neural networks, genetic algorithms etc.

The inference stage generates the results using a set of fuzzy rules, a list of conditional expressions "IF... THEN....". The aggregation of the results of each rule using a pondering system generates the result of the 
fuzzy inference process. The number of rules increases exponentially when the number of input rises. The results of the inference depend highly on how well the rules are formulated. The most important inference methods are Mamdani and Sugeno (Takagi-SugenoKang), respectively. The difference between them is that Mamdani uses fuzzy sets, whereas Sugeno systems use constant or linear functions as output.

Defuzzification is the stage where fuzzy variables are converted into crisp values because they cannot be used in practice. In this process, several membership function degrees are reduced to a single crisp value. There are different methods used for defuzzification: maxmembership principle, centroid method, weighted average method, mean-max membership, center of sums, center of largest area, first of maxima or lest of maxima.

\subsubsection{Fuzzy method applied to machining} optimization. Several studies have used fuzzy logic method in the optimization of machining processes. Surface roughness prediction models based on fuzzy inference systems were developed by Tseng [19], Kumanan [20], Roy [21] or Kovac [22].

\subsubsection{Surface roughness prediction in face milling} using fuzzy logic. A model for surface roughness prediction in high-speed face milling of an AZ61A magnesium alloy was developed by Chirita et al. [23]. The research has investigated the influence of process parameters and cooling conditions (Table 1).

Table 1. Milling parameters

\begin{tabular}{|c|c|c|}
\hline Parameter & Unit & Values \\
\hline Cutting speed $v_{c}$ & $\mathrm{~m} / \mathrm{min}$ & $600 \quad 1100 \quad 1600$ \\
\hline Feed per tooth $f_{z}$ & $\mathrm{~mm} /$ tooth & \begin{tabular}{lll|}
0.05 & 0.1 & 0.2 \\
\end{tabular} \\
\hline Depth of cut $a_{p}$ & $\mathrm{~mm}$ & 0.20 .5 \\
\hline Cooling method & & $\begin{array}{l}\text { dry cutting (1) MQL } \\
\text { compressed air (3) }\end{array}$ \\
\hline
\end{tabular}

Table 2. Comparison between measured and predicted roughness

\begin{tabular}{|c|c|c|c|c|c|c|}
\hline $\begin{array}{c}\text { Cutting } \\
\text { speed } \\
v_{c}\end{array}$ & $\begin{array}{c}\text { Feed } \\
f_{z}\end{array}$ & $\begin{array}{c}\text { Depth } \\
\text { of cut } \\
a_{p}\end{array}$ & Cooling & $\begin{array}{c}\text { Surfaces } \\
\text { roughness } \\
R_{a}\end{array}$ & $\begin{array}{c}\text { Predicted } \\
\text { roughness } \\
\text { value }\end{array}$ & Error \\
\hline 600 & 0.05 & 0.2 & 1 & 0.11 & 0.11 & 0 \\
\hline 600 & 0.2 & 0.5 & 1 & 0.152 & 0.15 & 0.002 \\
\hline 1100 & 0.1 & 0.2 & 1 & 0.236 & 0.217 & 0.019 \\
\hline 1600 & 0.2 & 0.5 & 1 & 0.372 & 0.4 & 0.028 \\
\hline 600 & 0.1 & 0.2 & 2 & 0.116 & 0.113 & 0.003 \\
\hline 600 & 0.2 & 0.5 & 2 & 0.128 & 0.117 & 0.11 \\
\hline 1100 & 0.05 & 0.5 & 2 & 0.084 & 0.0867 & 0.003 \\
\hline 1600 & 0.1 & 0.2 & 2 & 0.228 & 0.23 & 0.002 \\
\hline 1600 & 0.2 & 0.5 & 2 & 0.124 & 0.113 & 0.011 \\
\hline 600 & 0.05 & 0.2 & 3 & 0.124 & 0.11 & 0.014 \\
\hline 1100 & 0.1 & 0.2 & 3 & 0.100 & 0.1 & 0 \\
\hline 1100 & 0.2 & 0.5 & 3 & 0.198 & 0.2 & 0.002 \\
\hline 1600 & 0.05 & 0.2 & 3 & 0.100 & 0.103 & 0.003 \\
\hline 1600 & 0.02 & 0.5 & 3 & 0.230 & 0.22 & 0.010 \\
\hline
\end{tabular}

A total of 54 experiments resulted from the combination of the parameters and were performed on a vertical milling center Rapimill 700 with a $50 \mathrm{~mm}$ tool equipped with Sandvik inserts. The results are partially presented in Table 2.

In this study an adaptive neuro-fuzzy inference system (ANFIS) was developed in MATLAB using the Fuzzy Logic Toolbox. ANFIS is based on Sugeno fuzzy inference system but has adaptive learning capability given by the neural network element. The neural network is trained using a set of data and generates the membership functions for the inputs and the output using a backpropagation algorithm or a hybrid of backpropagation and the least squares method. The internal structure of ANFIS contains five layers with the following functions: fuzzification of input data, construction of fuzzy sets database, construction of the fuzzy rules, decision taking, defuzzification of the output (Figure 2).

This ANFIS is capable to make predictions on surface roughness $\mathrm{Ra}$, which is the output, based on four input variables corresponding to the process parameters (cutting speed vc, feed fz, depth of cut ap, cooling method). Each input has a number of membership functions equal to the number of levels, and the best results were obtained using a gaussian form (Figure 3).

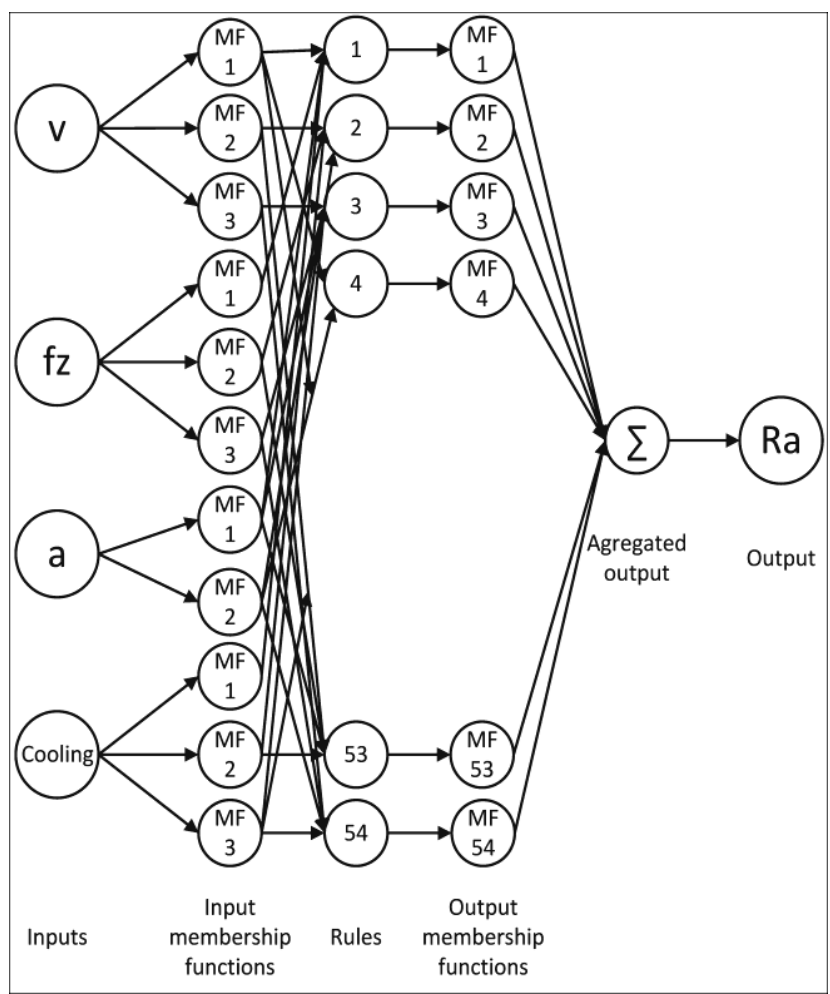

Fig. 2. Internal structure of ANFIS 

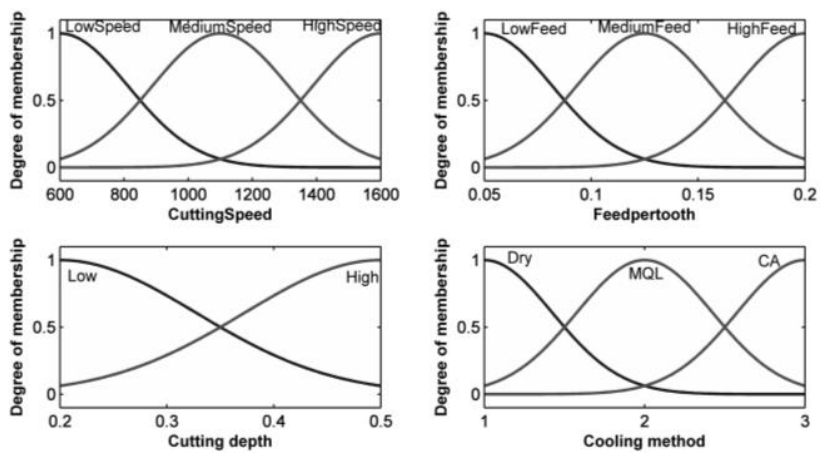

Fig. 3. Membership functions

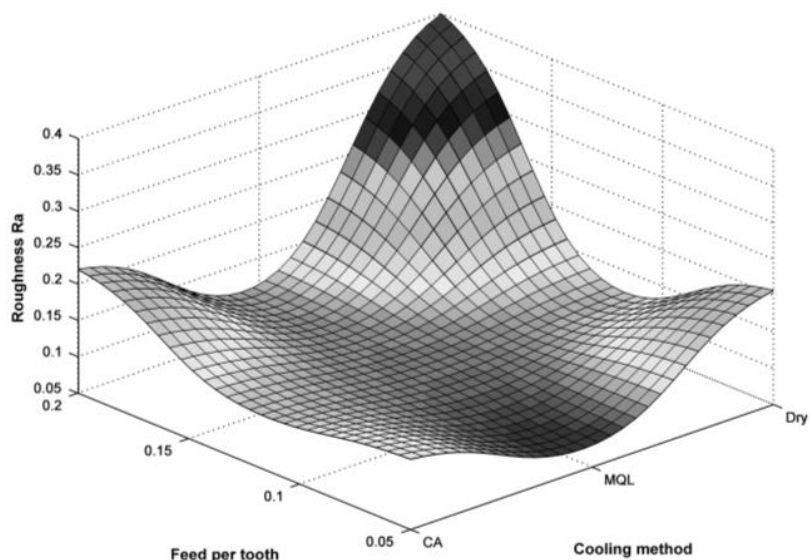

Fig. 4. Surface roughness prediction

Input data sets are used for training and calibration of the neural network that generated a total number of 54 conditional rules, which form the decisional part. The precision of predictions was quite good, with a root mean square error of 0.0119 , while the mean absolute percentage error was $5.25 \%$. A mapping of the predicted roughness represented as a continuous surface is presented in Figure 4.

\subsection{Design of experiments - Response surface method}

As a process subjected to a multitude of influences, machining is often modelled and analysed using statistical methods. Design of experiments (DOE) offer the means for structured planning of the experimental tests to collect appropriate data that can be further analysed statistically so that valid and objective conclusions can be formulated. There are a multitude of methodologies included in DOE, which make them a valuable tool for engineers and scientists. DOE methods are relatively simple to use while also powerful enough, thus they are widely used in machining studies. Using DOE techniques one can establish a statistical correlation between a set of input factors (variables), which are under control, and one or more outputs of the process operating in an uncertain environment. It becomes thus possible to designate some statistically significant factors of influence and to establish their optimal values necessary to achieve a desired output quality from the process. One of the important features of DOE is that several variables can be changed simultaneously so the influence of their interactions can be also established.

Response Surface Method (RSM) is one of the tools included in DOE. The term comes from the surface used for the representation of the process output when the input factors vary within their specified interval. The input variables are strictly controlled and combined into a matrix representing the experimental plan. Both quantitative and qualitative variables can be inputs in RSM, while their significance is determined using statistical analysis (ANOVA). Mathematical models can be derived using least square method from statistic regression.

Linear or quadratic equations are formulated using first or second order models:

$$
\begin{gathered}
Y=a_{0}+\sum_{i} a_{i} x_{i}+\sum_{i j} a_{i j} x_{i} x_{j}+C \\
Y=a_{0}+\sum_{i} a_{i} x_{i}+\sum_{i j} a_{i j} x_{i} x_{j}+\sum_{i} a_{i i} x_{i}^{2}+C
\end{gathered}
$$

where the terms of the equations are $Y$ - the response, $x_{i}$ - factors (variables), $x_{i} x_{j}$ - interactions, $C$ - free term (error fit), $a_{i}, a_{i i}, a_{i j}$ - regression coefficients.

Factor significance is established by analysis of variance (ANOVA). An F-test is performed under a null hypothesis: large values of F-ratios imply that the factor has high influence on the response, thus can be considered significant. Significance is determined according to a confidence interval established for a chosen $p$-value, which represents the probability that the F-test results could be obtained by random chance. Most studies use a $95 \%$ confidence interval, meaning that the null hypothesis is rejected if an F-value is large enough, so it corresponds to a $p$-value smaller than 0.05 .

Process optimization is obtained using desirability functions: the response $Y$ has a corresponding desirability function $d$ with values ranging in an interval $[0,1]$. When the response is closer to the target $d \rightarrow 1$, otherwise, the more it gets further from the target then $d \rightarrow 0$. Multiple responses optimization requires an overall desirability

$$
D=\sqrt[m]{\prod d_{i}}
$$

where $m$ is the number of responses [17].

\subsubsection{DOE applied to machining optimization. DOE} methods are the most employed for modelling and optimization of machining processes as they provide good results with relatively minimum efforts. Multiple parameters and machining outcomes have been analysed, simulated and optimised in various 
studies: surface roughness [15, 24, 25], cutting forces $[26,15]$, temperature [27] etc.

\subsubsection{Surface roughness prediction in face milling} using Response Surface Method. A central composite matrix was used to organise the experiments. According to this, there are three groups of design points: factorial points (corresponding to levels +1 and -1), central points (0 level, corresponding to the average), star points (levels $+\alpha$ and $-\alpha$ that assure the rotatability of the design). The most extreme values of the experimental factors are presented in Table 3. The values of the cutting parameters were chosen to comply with the recommendations of the cutting inserts manufacturer. The experimental plan contained a set of 60 trials, partially presented in Table 4 .

As previously mentioned, the tests were also carried on the Rapimill $700 \mathrm{CNC}$ vertical milling center equipped with the $50 \mathrm{~mm}$ tool. Dry cutting was first carried, followed by the set with SKF MQL cooling system.

Roughness is expressed as surface area roughness $S_{a}$ and was measured using a 3D optical profiler (Zygo ZeGage).

The main tool of DOE methods is ANOVA, which is used to discover the significant factors and interactions while also offering the means to establish the amount of each factor contribution to the total variability of the model.

Table 3. Experimental factors and the variation interval

\begin{tabular}{|l|l|c|c|}
\hline \multirow{2}{*}{ Factor } & \multirow{2}{*}{\begin{tabular}{l} 
Measurement \\
\cline { 2 - 3 }
\end{tabular}} & \multicolumn{2}{|c|}{ Level } \\
\cline { 3 - 4 } $\begin{array}{l}\text { A. Cutting speed, } \\
v_{c}\end{array}$ & $\mathrm{~m} / \mathrm{min}$ & 500 & 1000 \\
\hline $\begin{array}{l}\text { B. Feed per } \\
\text { tooth, } f_{z}\end{array}$ & $\mathrm{~mm} / \mathrm{\text {tooth }}$ & 0.08 & 0.30 \\
\hline $\begin{array}{l}\text { C. Depth of cut, } \\
a_{p}\end{array}$ & $\mathrm{~mm}$ & 0.40 & 1.60 \\
\hline D. Feed direction & - & Direct & Reversed \\
\hline E. Cooling & - & Dry cutting & MQL \\
\hline
\end{tabular}

Table 4. Results extracted from the experimental plan

\begin{tabular}{|c|c|c|c|c|c|}
\hline $\mathrm{A}$ & $\mathrm{B}$ & $\mathrm{C}$ & $\mathrm{D}$ & $\mathrm{E}$ & $S_{a}[\mu \mathrm{m}]$ \\
\hline 926.78 & 0.27 & 0.58 & Direct & Dry & 0.482 \\
\hline 750.00 & 0.08 & 1.00 & Direct & Dry & 0.174 \\
\hline 750.00 & 0.30 & 1.00 & Direct & Dry & 0.4 \\
\hline 573.22 & 0.27 & 1.42 & Reversed & Dry & 0.571 \\
\hline 750.00 & 0.19 & 1.00 & Reversed & Dry & 0.686 \\
\hline 926.78 & 0.27 & 0.58 & Direct & MQL & 0.491 \\
\hline 926.78 & 0.11 & 1.42 & Direct & MQL & 0.239 \\
\hline 573.22 & 0.27 & 1.42 & Direct & MQL & 0.37 \\
\hline 573.22 & 0.11 & 0.58 & Direct & MQL & 0.219 \\
\hline 500.00 & 0.19 & 1.00 & Direct & MQL & 0.364 \\
\hline 1000.00 & 0.19 & 1.00 & Direct & MQL & 0.552 \\
\hline 750.00 & 0.19 & 1.60 & Reversed & MQL & 0.412 \\
\hline 750.00 & 0.19 & 1.00 & Reversed & MQL & 0.281 \\
\hline 750.00 & 0.19 & 1.00 & Reversed & MQL & 0.271 \\
\hline 750.00 & 0.19 & 1.00 & Reversed & MQL & 0.299 \\
\hline
\end{tabular}

Table 5. RSM ANOVA - Surface area roughness $S_{a}$

\begin{tabular}{|l|l|l|l|l|l|l|}
\hline Source & df & $\begin{array}{l}\text { Sum of } \\
\text { squares }\end{array}$ & $\begin{array}{l}\text { Mean } \\
\text { square } \\
\text { s }\end{array}$ & $\begin{array}{l}\text { F- } \\
\text { value }\end{array}$ & $\begin{array}{l}\text { p- } \\
\text { value }\end{array}$ & \\
\hline Model & 9 & 5.00 & 0.5551 & 7.14 & $\begin{array}{l}< \\
0.0001\end{array}$ & significant \\
\hline $\begin{array}{l}\text { A - cutting } \\
\text { speed }\left(v_{c}\right)\end{array}$ & 1 & 0.0450 & 0.0450 & 0.5790 & 0.4503 & \\
\hline $\begin{array}{l}\text { B - feed per } \\
\text { tooth }\left(f_{z}\right)\end{array}$ & 1 & 2.58 & 2.58 & 33.17 & 0.0001 & \\
\hline $\begin{array}{l}\text { D - feed } \\
\text { direction }\end{array}$ & 1 & 0.3784 & 0.3784 & 4.87 & 0.0320 & \\
\hline E - cooling & 1 & 0.0002 & 0.0002 & 0.0030 & 0.9567 & \\
\hline A $\times \mathrm{E}$ & 1 & 0.3690 & 0.3690 & 4.74 & 0.0341 & \\
\hline B $\times \mathrm{D}$ & 1 & 0.3800 & 0.3800 & 4.89 & 0.0317 & \\
\hline $\mathrm{D} \times \mathrm{E}$ & 1 & 0.4438 & 0.4438 & 5.71 & 0.0207 & \\
\hline $\mathrm{A}^{2}$ & 1 & 0.3424 & 0.3424 & 4.40 & 0.0410 & \\
\hline $\mathrm{B}^{2}$ & 1 & 0.4295 & 0.4295 & 5.52 & 0.0228 & \\
\hline Residual & 50 & 3.89 & 0.0778 & & & \\
\hline Total & 59 & 8.88 & & & & \\
\hline
\end{tabular}

The results of the analysis are presented in Table 5 . Factors are considered significant if $p$-value is smaller than 0.005 , while the others are excluded from the model using a backward elimination criterion. Although some factors may be considered not significant, they were kept in the model because they are involved in significant interaction or quadratic terms. According to the results, the feed per tooth (B) is the most significant factor, with a contribution of $29.05 \%$, followed by feed direction (D) but with a much lower contribution of only $4.26 \%$. The significant interactions terms are feed direction - cooling $(\mathrm{D} \times \mathrm{E})$, feed per tooth - feed direction $(\mathrm{B} \times \mathrm{D})$ and cutting speed - cooling $(\mathrm{A} \times \mathrm{E})$, respectively, while the significant quadratic terms are feed per tooth $\left(\mathrm{B}^{2}\right)$ and cutting speed $\left(\mathrm{A}^{2}\right)$.

The influence of feed per tooth (B) on surface roughness is illustrated in Figure 5 and increased feed values results in higher values of surface roughness, thus lowering surface quality. Feed direction also modifies surface roughness: a reversed feed direction leads to increased roughness, as can be seen in Figure 6 . The reversed direction of the feed increases surface roughness to a greater extent for dry cutting than for MQL, as it can be observed from Figure 7. On the other side, for lower cutting speeds the use of MQL is more beneficial than dry cutting as it leads to better surface quality. When the cutting speed is increased, surface roughness is less influenced by the cooling conditions, as it can be observed from Figure 8 . 


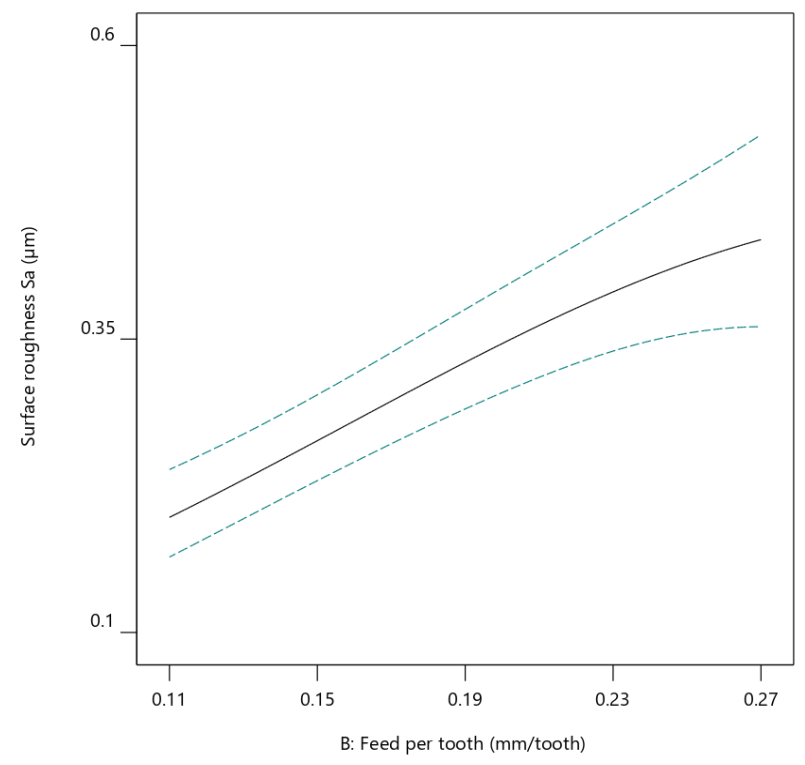

Fig. 5. Influence of feed per tooth on surface roughness

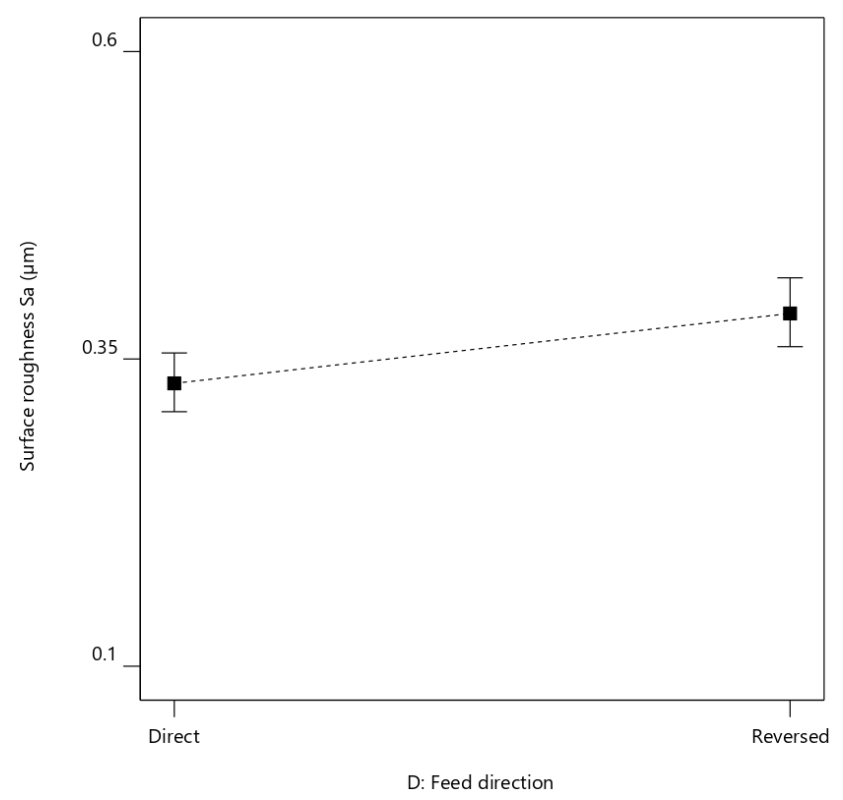

Fig. 6. Influence of feed direction on surface roughness

- $\quad$ Direct feed, MQL

$$
\ln \left(S_{a}\right)=-1.13536-0.004658 v_{c}+12.45691 f_{z}+3.36854 e-06 v_{c}^{2}-19.48771 f_{z}^{2}
$$

- Direct feed, dry cutting

$$
\ln \left(S_{a}\right)=-0.392249-0.005872 v_{c}+12.45691 f_{z}+3.36854 e-06 v_{c}^{2}-19.48771 f_{z}^{2}
$$

- Reversed feed, MQL

$$
\ln \left(S_{a}\right)=-0.616146-0.004658 v_{c}+9.65485 f_{z}+3.36854 e-06 v_{c}^{2}-19.48771 f_{z}^{2}
$$


- Reversed feed, dry cutting

$$
\ln \left(S_{a}\right)=0.470993-0.005872 v_{c}+9.65485 f_{z}+3.36854 e-06 v_{c}^{2}-19.48771 f_{z}^{2}
$$

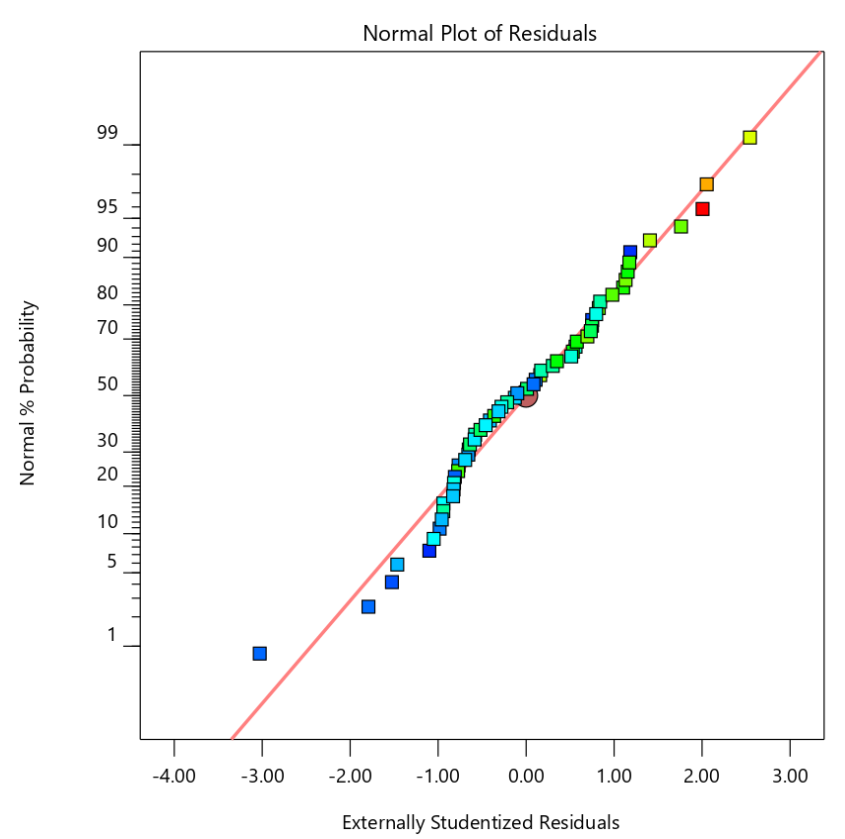

Fig. 9. Normal probability plot of residuals

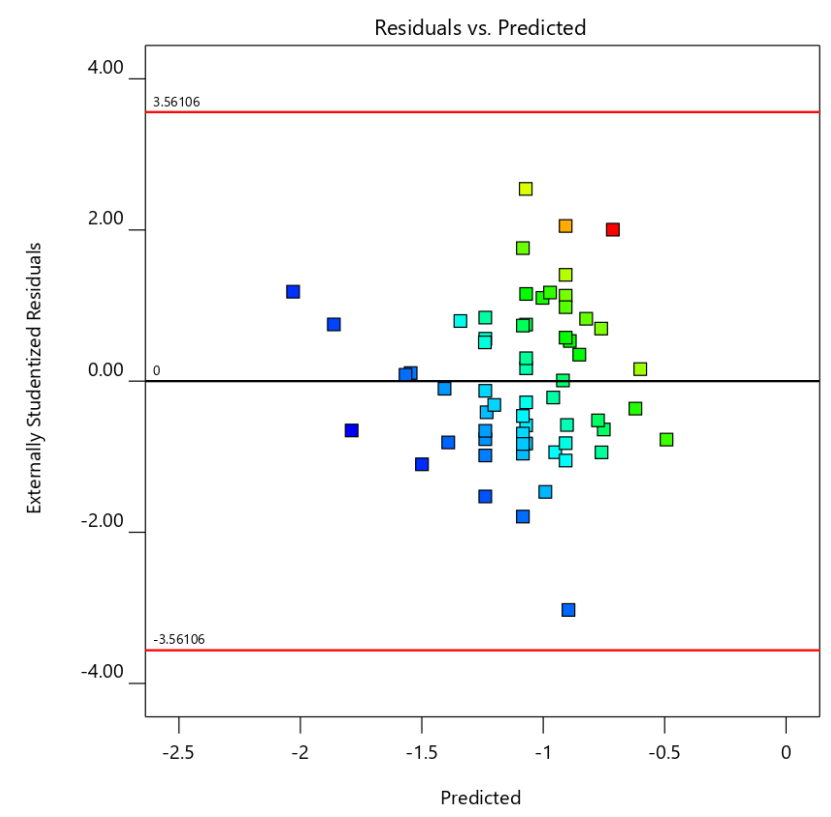

Fig. 10. Residuals vs predicted

The model can be diagnosed by examining the residuals. The normal probability plot following a straight line (Figure 9) reveals that the errors are normally distributed, while the residuals vs predicted plot (Figure 10) shows that the residuals are randomly scattered, without evident patterns, which means that the model and the results are not biased.

\section{CONCLUSIONS}

This paper offers a brief overview on some of the methods used in modelling and optimization of the milling process. Two models were presented for high-speed face milling of an AZ61A magnesium alloy. First model is based on an adaptive neurofuzzy inference system developed in MATLAB. The second model is based on Response Surface Model and offers the means to derive a mathematical representation of the process using statistical analysis. These methods are relatively easy to use, capable to integrate various control factors, sufficiently accurate, and offer the premises for the optimization of the process.

\section{REFERENCES}

1. Cui X., Zhao J., Tian X., (2013). Cutting forces, chip formation, and tool wear in high-speed face milling of AISI H13 steel with CBN tools, Int. J. Adv. Manuf. Technol., 64(9-12), pp. 1737-1749.

2. Grzesik W., (2017). Advanced Machining Processes of Metallic Materials: Theory, Modelling, and Applications, pp. 21, Elsevier, Amsterdam.

3. Elbah M., Laouici H., Benlahmidi S., Nouioua M., Yallese M. A., (2019). Comparative assessment of machining environments (dry, wet and $M Q L$ ) in hard turning of AISI 4140 steel with CC6050 tools, Int. J. Adv. Manuf. Technol., 105(5-6), pp. 2581-2597.

4. Goindi G. S., Sarkar P., (2017). Dry machining: A step towards sustainable machining - Challenges and future directions, J. Clean. Prod., 165, pp. 15571571.

5. Jamil M, Khan A. M., He N., Li L., Iqbal A., Mia M., (2019). Evaluation of machinability and economic performance in cryogenic-assisted hard turning of $\alpha-\beta$ titanium: a step towards sustainable manufacturing, Mach. Sci. Technol., 23(6), pp. 10221046.

6. Pereira O., Rodríguez A., Fernández-Abia A. I., Barreiro J., López de Lacalle L. N., (2016). Cryogenic and minimum quantity lubrication for an eco-efficiency turning of AISI 304, J. Clean Prod., 139, pp. 440-449.

7. Gupta M. K., Mia M., Pruncu C. I., Khan A. M., Rahman M. A., Jamil M., Sharma V. S., (2020). Modeling and performance evaluation of Al2O3, MoS2 and graphite nanoparticle-assisted MQL in turning titanium alloy: an intelligent approach, J.

Brazilian Soc. Mech. Sci. Eng., 42(4), 207.

8. Gupta M. K., Mia M., Singh G. R., Pimenov D. Y., Sarikaya M., Sharma V. S., (2019). Hybrid coolinglubrication strategies to improve surface topography and tool wear in sustainable turning of Al 7075-T6 alloy, Int. J. Adv. Manuf. Technol., 101(1-4), pp. 5569. 
9. Groppe M., (2018). Milling of Titanium, CIRP Encyclopedia of Production Engineering, Eds. Chatti S., Tolio T., pp. 1-6, Springer, Berlin.

10. Köhler J., (2018). Machinability of Aluminum and Magnesium Alloys, CIRP Encyclopedia of Production Engineering, Eds. Chatti S, Tolio T., pp. 1-6, Springer, Berlin.

11. Carou D., Rubio E. M., Davim J. P., (2015). Machinability of Magnesium and Its Alloys: A

Review, Traditional Machining Processes: Research Advances, Ed. Davim J. P., pp. 133-152, Springer,

Berlin.

12. Carou D., Rubio E. M., Davim J. P., (2014). Analysis of ignition risk in intermittent turning of UNS M11917 magnesium alloy at low cutting speeds based on the chip morphology, Proc. Inst. Mech. Eng. Part B J. Eng. Manuf., 229 (2), pp. 365-371.

13. Swetha C. V., Dumpala R., Anand K. S., Kondaiah V. V., Ratna S. B., (2018). Influence of heat treatment on the machinability and corrosion behavior of AZ91 Mg alloy, J. Magnes. Alloy, 6(1), pp. 52-58.

14. Koklu U., Coban H., (2020). Effect of dipped cryogenic approach on thrust force, temperature, tool wear and chip formation in drilling of AZ31 magnesium alloy, J. Mater. Res. Technol., 9(3), pp. 2870-2880.

15. Chirita B., Grigoras C., Tampu C., Herghelegiu E., (2019). Analysis of cutting forces and surface quality during face milling of a magnesium alloy, IOP Conf. Ser. Mater. Sci. Eng., 591, 012006.

16. Viswanathan R., Ramesh S., Subburam V., (2018). Measurement and optimization of performance characteristics in turning of $\mathrm{Mg}$ alloy under dry and MQL conditions, Meas. J. Int. Meas. Confed. 120, pp. 107-113.

17. Chirita B. A., (2021). Modeling and Optimization Process in Milling, Modeling and Optimization in Manufacturing: Toward Greener Production by Integrating Computer Simulation, Eds. Pruncu C. I., Jiang J., pp. 83-112, Wiley VCH, Weinheim.

18. Sivanandam S. N., Sumathi S., Deepa S.N., (2007). Introduction to Fuzzy Logic using MATLAB, Springer, Berlin.

19. Tseng T. L., Konada U., Kwon Y., (2016). A novel approach to predict surface roughness in machining operations using fuzzy set theory, J. Comput. Des. Eng., 3(1), pp. 1-13.

20. Kumanan S., Jesuthanam C. P., Kumar R. A., (2008). Application of multiple regression and adaptive neuro fuzzy inference system for the prediction of surface roughness, Int. J. Adv. Manuf. Technol., 35(7-8), pp.778-788.

21. Roy S. S., (2005). Design of adaptive neuro-fuzzy inference system for predicting surface roughness in turning operation, J. Sci. Ind. Res., 64(9), pp. 653659.
22. Kovac P., Rodic D., Pucovsky V., Savkovic B., Gostimirovic M., (2013). Application of fuzzy logic and regression analysis for modeling surface roughness in face milling, J. Intell. Manuf., 24(4), pp. 755-762.

23. Chirita B., Mustea G., Brabie G., (2015). A statistical analysis applied for optimal cooling system selection and for a superior surface quality of machined magnesium alloy parts, Proc. Inst. Mech. Eng. Part B-J. Eng. Manuf., 229(3), pp. 392-408.

24. Saini A., Chauhan P., Pabla B. S., Dhami S. S., (2018), Multi-process parameter optimization in face milling of Ti6Al4V alloy using response surface methodology, Proc. Inst. Mech. Eng. Part B-J. Eng. Manuf., 232(9), pp. 1590-1602.

25. Ghosh G., Mandal P., Mondal S. C., (2019). Modeling and optimization of surface roughness in keyway milling using ANN, genetic algorithm, and particle swarm optimization, Int. J. Adv. Manuf. Technol., 100(5-8), pp. 1223-1242.

26. Azizi M. W., Belhadi S., Yallese M. A., Mabrouki T., Rigal J. F., (2012). Surface roughness and cutting forces modeling for optimization of machining condition in finish hard turning of AISI 52100 steel, J. Mech. Sci. Technol., 26(12), pp. 4105-4114.

27. Suhail A. H., Ismail N., Wong S. V., Abdul Jalil N. A., (2011). Workpiece surface temperature for inprocess surface roughness prediction using response surface methodology, J. Appl. Sci., 11(2), pp. 308315.

Received: April 23, 2021 / Accepted: December 20, 2021 / Paper available online: December 25, 2021 () International Journal of Modern Manufacturing Technologies 